\title{
Foundry Technology and Services for Si Photonics
}

\author{
P. Dumon* and A. Khanna* \\ * Imec - Ghent University, Dept. of Information Technology, \\ Sint-Pietersnieuwstraat 41, 9000 Gent, Belgium
}

\begin{abstract}
We discuss the progress in development and offering of silicon photonic integration platforms based on $200 \mathrm{~mm}$ and $300 \mathrm{~mm}$ wafer technologies. Devices have capability for developing high-speed datacommunication, but are also used for life science applications.
\end{abstract}

\section{INTRODUCTION}

The promise of silicon photonics is to allow for chips integrating a large amount of photonic functionality, integration with electronics, and low cost for highvolume applications.

We discuss the technology platforms that have been developed in Europe (section II), the design aspects (section III), offering for R\&D (section IV) and packaging (section V).

\section{TECHNOLOGY PLATFORMS}

No less than 4 technology platforms have been developed in Europe that allow for sub-micron silicon photonic waveguide based circuits. A summary is given in table I. All of them have waveguides and passives devices such as couplers, splitters, fiber couplers and wavelength filter devices (WDM). Most of them also have carrier-based modulators and photodiodes, with bandwidths meeting requirements for $10 \mathrm{Gbps}$ or $25 \mathrm{Gbps}$ data-communication devices.

TABLE I: OVERVIEW OF EUROPEAN SI PHOTONIC PLATFORMS

\begin{tabular}{|c|c|c|c|c|}
\hline $\begin{array}{c}\text { Company/ } \\
\text { institute }\end{array}$ & $\begin{array}{c}\text { Wafer } \\
\text { scale }\end{array}$ & Waveguides & Modulators & Photodiodes \\
\hline Imec & $\begin{array}{c}200 \mathrm{~mm} \\
300 \mathrm{~mm}\end{array}$ & $\begin{array}{c}\mathrm{X} \\
\mathrm{X}\end{array}$ & $\begin{array}{c}\mathrm{X} \\
\text { (development) }\end{array}$ & $\begin{array}{c}\mathrm{X} \\
\text { (development) }\end{array}$ \\
\hline CEA-Leti & $200 \mathrm{~mm}$ & $\mathrm{X}$ & $\mathrm{X}$ & $\mathrm{X}$ \\
\hline $\begin{array}{c}\text { IHP } \\
\text { Microelectronics }\end{array}$ & $200 \mathrm{~mm}$ & $\mathrm{X}$ & - & - \\
\hline $\begin{array}{c}\text { ST } \\
\text { Microelectronics }\end{array}$ & $300 \mathrm{~mm}$ & \multicolumn{3}{|c|}{ (development) } \\
\hline
\end{tabular}

For example, Imec's 200mm wafer si photonics platform has the following characteristics:

TABLE II: Imec si photonics platform characteristics

\begin{tabular}{|l|l|}
\hline Substrate & $\begin{array}{l}\text { 220nm SOI (ultra-flat possible) } \\
+160 \mathrm{~nm} \text { poly-Si areas }\end{array}$ \\
\hline Technology & 3 mask level SOI + 2 mask level poly \\
& patterning \\
& Implants and contacts \\
& Ge epitaxy and implantation \\
& Cu Metall wiring \\
& Al bondpads \\
\hline Waveguide devices & Waveguides: $0.3-3 \mathrm{~dB} / \mathrm{cm}$ \\
\hline
\end{tabular}

\begin{tabular}{|l|l|}
\hline & $\begin{array}{l}50 / 50 \text { splitters, 2x2 couplers and } \\
\text { power taps } \\
\text { WDM devices : >100GHz channel } \\
\text { spacing, down to 0.5dB IL and -25dB } \\
\text { cross-talk [2][3] }\end{array}$ \\
\hline Fiber couplers & $\begin{array}{l}\text { 6dB (standard) and 2.2dB (advanced) } \\
\text { coupling loss [4] }\end{array}$ \\
\hline High-speed modulators & $\begin{array}{l}\text { Mach-Zehnder } \\
>10 \mathrm{Gbps}[5] \\
\text { Compact ring modulators }>10 \mathrm{Gbps}\end{array}$ \\
\hline Ge photodiode & $\begin{array}{l}\text { >20GHz bandwidth } \\
\text { Dark current down to }<100 \mathrm{nA}\end{array}$ \\
\hline
\end{tabular}

Even though most of the platforms are being developed with short-range communication applications in mind, also biosensor, monitoring and life science applications are being demonstrated by users.

\section{FOUNDRY OFFERING}

The technologies are available directly from the companies/institutes for prototyping and development of custom products. Even though Imec, CEA-Leti and IHP are research institutes, they can support customers through the development chain from idea to smallvolume manufacturing. For volume applications, the bridge to commercial foundries is made with the customer.

In order to offer these expensive wafer scale technologies to small-scale users as well, we have set-up ePIXfab [6]. ePIXfab is a consortium of Imec (Belgium), CEA-Leti (France), IHP (Germany), VTT (Finland), Tyndall Institute (Ireland) and TNO (The Netherlands) and in collaboration with CMC (Canada).

ePIXfab has a range of activities to lower the cost of access for universities, research institutes small and medium sized companies and R\&D labs of small and large companies alike:

- Multi-project wafer runs are organized in Imec, CEA-Leti and IHP technologies. These multi project wafers are made accessible through Europractice [7]. CMC [8] is offering the MPW runs to Canadian universities and a support center is being setup at CETC38 in China.

- As discussed in section IV, fiber pigtailing and packaging solutions are made available for easier testing and demonstration of applications. 
- ePIXfab organizes training weeks two times per year as well as several webinars and workshop events.

- Small and medium sizes enterprises can contact ePIXfab to perform an initial feasibility study (on paper) for using silicon photonics in their application.

- Several partners, including TNO and Imec, and design houses such as VLC Photonics [9], offer design services

\section{Packaging}

Since 2012, through ePIXfab also first solutions for packaging are publicly offered for chips made through the MPW service. Tyndall Institute (Ireland) has developed a set of technologies for fiber attachment and housing. Packaging of devices including modulators is currently under development, as well as integration of laser sources in the package. We are working enabling passive alignment on this platform, as well as enabling packaging of larger volumes with industry suppliers.

Both single fibers and 8-fiber arrays can currently be attached to the silicon photonic chips, using grating couplers though maintaining a flat package. Design rules are available for designers so that they can easily meet the requirements of Tyndall Institute. By standardizing on a solution, the development costs and most of the nonrecurring engineering costs are shared amongst users. However, a certain level of flexibility is still possible in order to meet the application requirements of the individual user.

\section{ConcLusions}

We developed powerful silicon photonic integration platforms based on $200 \mathrm{~mm}$ and $300 \mathrm{~mm}$ wafer scale technologies, with devices such as waveguides, couplers, fiber couplers, high-speed modulators, tuning elements and high-speed photodiodes. Design kits and libraries are being developed allow both circuit-level and custom design into these technologies. These platforms are available for prototyping as well as manufacturing. Costeffective access to standardized platforms for $R \& D$ is enabled by ePIXfab using multi-project wafers, and packaging solutions are offered in order to ease testing and demonstration of applications.

\section{REFERENCES}

[1] W. Bogaerts and S. Selvaraja, "Compact Single-mode Silicon Hybrid Rib/Strip Waveguide with Adiabatic Bends", IEEE Photonics Journal, 3(3), p. 422-432, May 2011

[2] W. Bogaerts, S. Selvaraja, P. Dumon, J. Brouckaert, K. De Vos, D. Van Thourhout and R. Baets, "Silicon-onInsulator Spectral Filters Fabricated with CMOS Technology", J. Selected Topics in Quantum Electronics, 16 (1), p.33-44, 2010

[3] S. Pathak, M. Vanslembrouck, P. Dumon, D. Van Thourhout and W. Bogaerts, "Optimized Silicon AWG with Flattened Spectral Response Using an MMI Aperture", Journal of Lightwave Technology, 31 (1), p. 87 93, January 2013

[4] Y. Li, D. Vermeulen, Y. De Koninck, G. Yurtsever, G. Roelkens and R. Baets, "Compact grating couplers on silicon-on-insulator with reduced backreflection", Optics Letters 37(21), p. 4356-4358, November 2012

[5] H. Yu, M. Pantouvaki, J. Van Campenhout, D. Korn, K. Komorowska, P. Dumon, Y. Li, P. Verheyen, P. Absil, L. Alloatti, D. Hillerkuss, J. Leuthold, R. Baets and W. Bogaerts, "Performance tradeoff between lateral and interdigitated doping patterns for high speed carrierdepletion based silicon modulators", Optics Express 20(12), p. 12926-12938, June 2012

[6] See www.epixfab.eu

[7] See www.europractice-ic.com

[8] See www.cmc.ca

[9] See www.vlcphotonics.com 